\title{
Association between bread baking in wood tenor ovens and incidence and control of bronchial asthma in Ardabil, Iran, in 2013
}

\author{
Dashti S, MSc ${ }^{1}$, Dashti F, BSc ${ }^{2}$, Dashti A, BSc ${ }^{3}$, Shahmari M, $\mathrm{MSc}^{1}$ \\ 1- MSc in Nursing, Dept. of Medical Surgery, Faculty of Nursing and Midwifery, Tabriz University of Medical Sciences, \\ Tabriz, Iran. 2- BSc in English Language Translation, Dept. of Literature and Foreign Languages, Faculty of Humanities \\ Sciences, Ardabil Payame-Noor University, Ardabil , Iran. 3- BSc of Student in Computer Software Engineering, Dept. of \\ Information Technology, Faculty of Technical and Engineering, Ardabil Payame-Noor University, Ardabil , Iran.
}

\begin{abstract}
Received: February 2016, Accepted: May 2016

Background: Asthma is a chronic multifactorial disease with a high prevalence. Among asthma risk factors, the effect of baking in wood tenor ovens (traditional form of baking) on bronchial asthma is still debated. The aim of this study was to determine the association between baking in wood tenor ovens and incidence and control of bronchial asthma.

Materials and Methods: This descriptive study was conducted on 109 patients with asthma referring to Imam Khomeini Hospital in Ardabil, Iran, in 2013. Asthma Control Questionnaire (ACQ) was used to evaluate asthma control. Patients' asthma control was individually evaluated and compared with particular attention to history of baking in wood tenor ovens.Chi-square and Tau-Kendall tests were used to analyze the data in SPSS software.

Results: Of the 109 patients, $45.9 \%$ had a history of baking in wood tenor ovens. Patients with uncontrolled asthma constituted the largest volume of the sample (60.6\%). There was no significant correlation between baking in wood tenor ovens and asthma occurrence $(\mathrm{P}>0.05)$. However, there was a significant correlation between baking in wood tenor ovens and asthma control (error coefficient $<0.10$ ).

Conclusions: According to the results, although the history of baking in wood tenor ovens has no effect on asthma occurrence, it has a correlation with asthma control status. Therefore, it is necessary to raise community awareness about the effect of baking on asthma control status.
\end{abstract}

Keywords: Asthma, Bread, Occupational, Incidence.

\section{Introduction}

Asthma is a chronic inflammatory respiratory disease characterized by reversible airflow obstruction and airway hyper responsiveness (1). World Health Organization (WHO) has projected asthma deaths for 2015 and 2030 in the Eastern Mediterranean Region as 20000 and 27000 , respectively (2). The prevalence of asthma in Iran is much higher than the international estimation (3). Asthma is a multifactorial disease and is influenced by both genetic and environmental factors (1). Environmental air pollution can cause bronchial asthma. Biomass and solid fuels are a major source of indoor air pollution (4). One risk factor in asthma that causes indoor air pollution is bread baking in a wood tenor oven(5). In the traditional form of baking, due to the use of simple and wood tenor ovens in indoor spaces without proper ventilation, severe air pollution is caused (6).

A high percentage of the world population burn wood and other biomass fuels for baking and large crowds of women are exposed to high levels of indoor air pollution (7).

\footnotetext{
Corresponding author: Seemin Dashti, Dept. of Medical Surgery, Faculty of nursing and midwifery, Tabriz University of medical sciences, Tabriz, Iran. Email: dashtiseemin@gmail.com
} 
Exposure to biomass fuel, such as wood, reduces lung function and increases the prevalence of respiratory symptoms. Moreover, these effects have been associated with the duration and magnitude of exposure and are exacerbated by tobacco smoke (8). According previous studies on baker's asthma, there are some reasons for the probability of association between baking and asthma. One of these reasons is wood burning smoke in tenor ovens (in traditional baking) $(9,10)$. A history of using biomass fuels for indoor cooking significantly increased the risk of asthma (1).

Thus, bread baking is a threat to human health. Baker's asthma is classified as occupational asthma (5). In addition, the prevalence of asthma is increasing among bakers and most occupational asthma symptoms are observed among those who have prior work experience in baking (11). The increased risk of baker's asthma is associated with the use of wood fuel (12).

According to Smith et al., people who were exposed to wood fuel inhaled the equivalent of 2 packs of cigarette smoke per day (13). A significant number of Iranian women were found to suffer from chronic respiratory disease and no known risk factor was found in their history except long-term work experience with wood tenor ovens (14). However, some researchers did not find significant differences in pulmonary functions between bakers and non-bakers $(14,15)$. Whether baking in wood tenor ovens (masonry oven)is a risk factor for asthma is disputed by medical sciences researchers. Increasing community awareness about effects of bread baking in wood tenor ovens will assist in the management of asthma among asthma patients and its prevention among bakers. Due to importance of this issue and inefficiency of studies on the effect of traditional baking on asthma, this study was conducted in order to investigate the association between traditional bread baking and the prevalence and management of asthma.

\section{Material and Methods}

This descriptive study was conducted after obtaining approval from the School of Nursing and Midwifery and the Ethics Committee (ethical code 1922) of Tabriz University of Medical Sciences, Iran, and coordination with Imam Khomeini Hospital authorities in Ardabil, Iran. The statistical society of this study included all asthma patients of over 12 years of age in Ardabil. All adult patients who referred to Imam Khomeini Hospital in Ardabil from early March 2012 to late September 2013were enrolled in the study. Ultimately,109 patients were enrolled and evaluated. The inclusion criteria consisted of referral to Imam Khomeini Hospital during the study period and diagnosis with asthma by a lung disease professional. The exclusion criterion was unwillingness to participate in the study. Asthma was diagnosed by an expert doctor and based on spirometry paraclinical tests results and clinical symptoms.

Subjects were selected through convenience sampling. The purpose of the study was explained to the patients and informed consent forms were obtained from them. The data collection tools included a demographic information and the form of history of bread baking in wood tenor ovens and the Asthma Control Questionnaire (ACQ). The ACQ was used to determine the status of asthma control in patients. The ACQ was evaluated using the Pearson correlation coefficient, which showed strong evaluative and discriminative properties and that it can be used with confidence to measure asthma control (16). The internal correlation, reliability, and stability of ACQ with the ICC (Intraclass Correlation Coefficient) index were verified (Cronbach's $\alpha$ $=0.894)$. Adequacy of asthma control in patients was studied separately, and then, was compared in terms history of baking in wood tenor ovens. In order to analyze data, SPSS software (version 16, SPSS Inc., Chicago, IL, USA) was used. In order to study the significance of the correlation between baking in wood tenor ovens and asthma control, Tau- 
Kendall correlation test was used. Chi-square test was used to study the association of history of baking in wood tenor with asthma. In this research, the confidence level was $95 \%$. In other words, error level of $5 \%$ was predicted in the calculation of results.

The status of asthma control among the participants was classified using the mean score of 6 questions of the ACQ questionnaire. Subjects with mean score of 0.75 to 1.5 were on the controlled and uncontrolled border; below this threshold was controlled and above it was uncontrolled. The validity and reliability of the questionnaire was confirmed by these studies $(16,17)$.

Confounding factors in this study were smoking status, indoor or outdoor baking, baking duration, the type of flour used in baking, and history of farming and animal husbandry inpatients. All of these factors affect the incidence of asthma and, due to the retrospective nature of the study, they could not be controlled.

Table 1: Subjects with asthma in Imam Khomeini Hospital in Ardabil, Iran, during 2012-2013

\begin{tabular}{ccc}
\hline & Frequency & \% \\
\hline Uncontrolled & 66 & 60.6 \\
\hline Border & 17 & 15.6 \\
\hline Controlled & 26 & 23.8 \\
\hline Total & 109 & 100.0
\end{tabular}

\section{Results}

During the study, 109 adults with asthma entered the study. Mean age of subjects was $40.91 \pm 14.78$. Among the study participants, $45.9 \%$ had a history of baking in wood tenor ovens. Patients with uncontrolled asthma constituted the largest volume of the sample $(60.6 \%)$ (Table 1). Moreover, $47.0 \%$ of subjects with uncontrolled asthma had a history of baking in wood tenor ovens. The history of tobacco smoke exposure was reported by $31.2 \%$ of all patients. Furthermore, $48.6 \%$ of those who had a history of baking were exposed to tobacco smoke. In this study, the correlation of baking with the incidence and control of asthma were evaluated.

Tau-Kendall Through the comparison of the significance level obtained by error factor of lower than 0.10 , it can be concluded that there was a significant association between baking in wood tenor ovens and asthma control (Table 2).

In order to evaluate the correlation of baking in wood tenor ovens with the incidence of asthma, chi-square test was used. In addition, in order to evaluate this test, an agreed table was used. Table 3 is an agreed table which shows expected values and observed values. Chi-square test was used in order to study the association between expected and observed values. No significant association was found between the history of baking in wood tenor ovens and the occurrence of asthma $(\mathrm{P}>0.05)$. Therefore, the null hypothesis was confirmed $(\mathrm{P}>0.05)$. Therefore, positive history of baking in wood tenor ovens has no significant effect on asthma occurrence.

Table 2: Tau-Kendall correlation between variables

\begin{tabular}{ccccc}
\hline & & Asthma control & Baking history & Smoking exposure \\
\hline \multirow{2}{*}{$\begin{array}{c}\text { Asthma } \\
\text { control status }\end{array}$} & Correlation coefficient & 1.000 & & \\
\cline { 2 - 5 } & Significance level &. & & \\
\hline \multirow{2}{*}{$\begin{array}{c}\text { Baking } \\
\text { history }\end{array}$} & Correlation coefficient & -0.158 & 1.000 & \\
\cline { 2 - 5 } $\begin{array}{c}\text { Smoking } \\
\text { exposure }\end{array}$ & Significance level & 0.087 & 0.096 & 1.000 \\
\cline { 2 - 5 } & Correlation coefficient & -0.018 & 0.321 &. \\
\hline
\end{tabular}


Table 3: The association of baking with different asthma conditions $(P>0.05)$

\begin{tabular}{|c|c|c|c|c|c|}
\hline & & & \multicolumn{3}{|c|}{ Baking history } \\
\hline & & & Negative & Positive & All \\
\hline \multirow{12}{*}{$\begin{array}{l}\text { Asthma } \\
\text { condition }\end{array}$} & \multirow{4}{*}{ Uncontrolled } & Observed number & 35 & 31 & 66 \\
\hline & & Expected number & 35.7 & 30.3 & 66.0 \\
\hline & & $\%$ within asthma & $53.0 \%$ & $47.0 \%$ & $100.0 \%$ \\
\hline & & $\%$ within baking & $59.3 \%$ & $62.0 \%$ & $60.6 \%$ \\
\hline & \multirow{4}{*}{ Border } & Observed & 10 & 7 & 17 \\
\hline & & Expected & 9.2 & 7.8 & 17.0 \\
\hline & & $\%$ within asthma & $58.8 \%$ & $41.2 \%$ & $100.0 \%$ \\
\hline & & $\%$ baking & $16.9 \%$ & $14.0 \%$ & $15.6 \%$ \\
\hline & \multirow{4}{*}{ Total } & Observed & 14 & 12 & 26 \\
\hline & & Expected & 14.1 & 11.9 & 26.0 \\
\hline & & $\%$ within asthma & $53.8 \%$ & $46.2 \%$ & $100.0 \%$ \\
\hline & & $\%$ within baking & $23.7 \%$ & $24.0 \%$ & $23.8 \%$ \\
\hline
\end{tabular}

\section{Discussion}

The results of table 2, which were obtained using the Tau-Kendall correlation test, show a significant negative correlation between baking history and asthma control. Therefore, the results of this study showed that history of baking in asthma suffering patients had a significant inverse association with controlling their asthma (error factor $<0.10$ ). Our study results were consistent with the results of some previous researchers. Beheraet al. studied the effect of exposure to domestic cooking fuels on bronchial asthma (18). They found that exposure to biomass fuel and liquefied petroleum gas for domestic cooking impacts airway function and symptoms of bronchial asthma (18). The chi-square test results showed that there was no significant association between baking history and asthma occurrence $(\mathrm{P}<0.05)$. Therefore, although $47 \%$ of study subjects had baking history, there was no significant association between this variable and asthma occurrence. Our study results were also consistent with that of some other researchers. Zahmatkeshet al. reported in their study that there was no significant difference in pulmonary tests between bakers who had worked with non-wood fuels and the control group (nonbakers)(14). Thacher et al., in their cross- sectional study, reported that exposure to biomass fuel smoke was not associated with asthma symptoms or airway obstruction (15).However, the findings of some studies were contrary to our results. In this regard, we can refer to the study by Aminiet al. that showed a significant correlation between the occurrence of respiratory diseases and the use of solid fuels for cooking (19). Furthermore, the study by Amraet al. showed the effectiveness of biofuel use in baking on the prevalence of respiratory disease (20). They also introduced the exposure to smoke of organic fuels as pathogens (20). Walusiaket al. stated that the incidence of occupational asthma in bakery disciples is high and it increases with increase in duration of employment (21). Brisman et al. evaluated asthma in bakery workers (22). They noted that the risk of asthma increased due to exposure to inhalable dust (dough making or bread forming) which attributed to occupational exposure (22). In the studies by Orozco-Levi and Ahtar, a consistent association was found between biomass burning and respiratory symptoms $(23,24)$. Trevor et al., in a review article, stated that exposure to biomass fuel smoke causes respiratory diseases such as asthma that is associated with household air pollution (25). Moreover, Uzun et al., in 
their study, observed a significant association between symptoms of chronic asthma and biomass fuel usage in rural women (26).

Considering the importance of this issue and the conflicting results of studies in this regard, further studies are necessary in order to accurately clarify the association between wood tenor baking history and asthma occurrence and control. Therefore, it is suggested that future researches be conducted on the occurrence of asthma among bakers classified based on type of fuel and flour used for bread. Furthermore, it is recommended that future studies focus on the association of exposure to tobacco smoke and exposure to wood fuel with asthma.

\section{Conclusion}

According to our results, the largest volume of the study sample with a history of traditional bread baking had uncontrolled asthma compared to those who had no baking history. However, it was found that baking in wood tenor ovens (traditional form of baking)has no effect on the occurrence of asthma, but it has a correlation with asthma control status. Bread baking in Iran in most casesis conducted in the traditional form and using a wood tenor oven. Thus, it is necessary to raise community awareness about its effect on asthma control status.

\section{Acknowledgements}

The authors would like to thank the Research Deputy of Tabriz University of Medical Sciences for the approval and funding of this study. They would also like to thank Dr. Mohammad Mirza Aqazadeh for his cooperation in this study and all asthma patients and other individuals who participated and helped in this study.

Conflict of Interest: None declared

\section{References}

1. Barry AC, Mannino DM, Hopenhayn C, Bush H. Exposure to indoor biomass fuel pollutants and asthma prevalence in Southeastern Kentucky: results from the burden of lung disease (BOLD) study. J Asthma 2010;47(7):735-41.

2. World health organization (WHO). Asthma prevalence. Cairo: Regional Office for the Eastern Mediterranean [Internet]. 2014 [Cited 2014 June 9]. Available from: http://www.emro.who.int/healthtopics/asthma/index.html

3. Masoli M, Fabian D, Holt S, Beasley R; Global Initiative for Asthma (GINA) Program. The global burden of asthma: executive summary of the GINA Dissemination Committee report. Allergy 2004; 59(5):469-78.

4. Agrawal S. Effect of indoor air pollution from biomass and solid fuel combustion on prevalence of self-reported asthma among adult men and women in India: findings from a nationwide large-scale cross-sectional survey. J Asthma 2012; 49(4):355-65.

5. Smith KR. National burden of disease in India from indoor airpollution. Proc Natl Acad Sci India Sect B Biol Sci 2000; 97(24):13286-93.

6. Baur X, Weiss W, Sauer W, Fruhmann G, Kimm KW, Ulmer WT, et al. Baking ingredients as a contributory cause of baker's asthma. Dtsch Med Wochenschr 1988; 113(33):1275-8 .

7. Diette GB, Accinelli RA, Balmes JR, Buist AS, Checkley W, Garbe P, et al. Obstructive lung disease and exposure to burning biomass fuel in the indoor environment. Glob Heart 2012;7(3):265-70.

8. da Silva LF, Saldiva SR, Saldiva PH, Dolhnikoff M; Banderia Cientifica Project. Impaired lung function in individuals chronically expoused to biomass combustion. Environ Res 2012; 112:111-7.

9. Amoli K. Bronchopulmonary disease in Iranian house wives chronically exposed to indoor smoke. Eur Respir J 1998; 11(3):65963.

10. Weiss W, Vogelmeier C, Görg A. Electrophoretic characterization of wheat grain allergens from different cultivars involved in bakers' asthma. Electrophoresis 1993; 14(8):805-16.

11. Houba R, Doekes G, Heederik D. Occupational respiratory allergy in bakery workers: A review of the literature. Am J Ind Med 1998; 6(34):529-46.

12. Van Miert E, Sardella A, Nickmilder M, Bernard A. Respiratory effects associated with wood fuel use: a cross-sectional biomarker 
study among adolescents. PediatrPulmonol2012; 47(4):358-66.

13. Smith KR, Aggarwal AL, Dave RM.Air pollution and rural biomass fuel in developing countries: A pilot village study in India and implication for research and policy. Atmos Envion 1967; 17(11):2343-62.

14. Zahmatkesh MM, Afshar B, Ehteshami Afshar A. Pulmonary function tests in bakers of Tehran and Comparison with Control Group. Razi Journal of Medical Sciences 1999; 6(2):128-33.

15. Thacher JD, Emmelin A, Madaki AJ, Thacher TD. Biomass fuel use and the risk of asthma in Nigerian children. Respir Med 2013; 107(12):1845-51.

16. Juniper EF, O'Byrne PM, Guyatt GH, Ferrie PJ, King DR. Development and validation of questionnaire to measure asthma control. Eur Respir J 1999; 14(4):902-7.

17. Guyatt GH, Kirshner B, Jaeschke R. Measuring health status: what are the necessary measurement properties? J Clin Epidemiol 1992; 45(12):1341-5.

18. Behera D, Chakrabarti T, Khanduja KL. Effect of exposure to domestic cooking fuels on bronchial asthma. Indian $\mathrm{J}$ Chest Dis Allied Sci 2001; 43(1):27-31.

19. Amini F, Abdollahzade N, Ganbari M, Gaderpoor M, Malekafzali SH, Karegar H. Relative risk of respiratory infection among rural households using solid fuel in West
Azerbaijan Province and evaluation of its influencing factors. Journal of Health 2015; 5(4):345-54.

20. Amra B, Gholshan M, Shirian R. Risk factors for chronic bronchitis among women in Sharekord, Iran. Tanaffos 2002; 1(3):19-23.

21. Walusiak J, Hanke W, Górski P, Pałczyński C. Respiratory allergy in apprentice bakers: do occupational allergies follow the allergic march? Allergy 2004; 59(4):442-50.

22. Brisman J, Jarvholm B, Lillienberg L. Exposure-response relations for selfreported asthma and rhinitis in bakers. Occup Environ Med 2000; 57(5):335-40.

23. Orozco-Levi M, Garcia-Aymerich J, Villar J, Ramirez-Sarmiento A, Anto JM, Gea J. Wood smoke exposure and risk of chronic obstructive pulmonary disease. EUR Respir J 2006; 27(3):542-6.

24. Ahtar T, Ullah Z, Khan MH, Nazli R. Chronic bronchitis in women using solid biomass fuel in rural Peshawar, Pakistan. Chest 2007; 132:1472-5.

25. TrevorJ, Antony V, Jindal SK. The effect of biomass fuel exposure on the prevalence of asthma in adults in India - review of current evidence. J Asthma 2014; 51(2):136-41.

26. Uzun K, Özbay B, Ceylan E, Gencer M, Zehir I. Prevalence of chronic bronchitis-asthma symptoms in biomass fuel exposed females. Environ Health Prev Med 2003; 8(1):13. 